\title{
Portal Universitário: Acesso e Uso no Ensino da Dermatologia
}

\section{University Portal: Access and Use in Dermatology Education}

Kátia Sheylla Malta Purim ${ }^{I}$

\section{PALAVRAS-CHAVE}

- Medicina;

- Dermatologia;

- Educação Médica;

- Acesso à Informação;

- Estudantes.

\section{KEYWORDS}

- Medicine;

- Dermatology;

- Medical Education;

- Information Access;

- Students.

\begin{abstract}
RESUMO
Modalidades de aprendizagem virtual combinadas com métodos convencionais de ensino podem contribuir na educação médica. Este estudo investigou o perfil de acesso e uso de portal universitário no ensino da Dermatologia. Trata-se de pesquisa quantitativa com questionário para avaliar emprego do portal universitário, perfil tecnológico dos estudantes, necessidades informacionais e uso de base de dados. A amostra foi composta por 122 acadêmicos na faixa etária de 23,7 $\pm 3,1$ anos, com domínio da língua inglesa $(93,4 \%)$ e acesso ao portal via internet domiciliar $(77,9 \%)$ e dispositivos móveis $(43,4 \%)$. As vantagens foram obtenção do conteúdo das aulas, recursos didáticos oferecidos e disponibilidade permanente. As dificuldades residiram em disponibilidade de rede no hospital-escola, aspectos técnicos e operacionais. Os acessos preferidos foram: aulas ilustradas, cronograma de provas e trabathos, avisos editados, leituras obrigatórias, artigos, textos anexados e consultas a bibliotecas virtuais e revistas médicas. As bases de dados mais utilizadas foram: UpToDate (84,4\%), Pubmed (77,9\%) e Scielo 94 (77\%). O portal atendeu as demandas informacionais dos graduandos,porém a utilidade percebida e a facilidade de uso deste recurso didático podem ser potencializadas para aplicação mais ampla na medicina.
\end{abstract}

\begin{abstract}
Combined with conventional learning methods, forms of e-learning can help improve medical education. This study investigated the access profile and use of a University portal by Dermatology students. Quantitative research with a questionnaire was conducted to assess use of the University portal, the students' technological profile, informational needs and use of the database. The sample was formed by 122 students aged $23.7 \pm 3.1$ years, who spoke English (93.4\%) and had access to the portal via internet at home $(77.9 \%)$ and mobile devices $(43.4 \%)$. The advantages identified were obtaining the materialfrom classes, educational resources offered and permanent availability. The difficulty resided in network availability at the teaching hospital as well astechnical and operational aspects. The most commonly accessed resources were: illustrated lessons, exam and coursework calendars, published bulletins, compulsory reading lists, articles and attached texts and consultations in thevirtual libraries and medical journals. The most-used databases were: UpToDate(84.4\%), PubMed (77.9\%) and Scielo 94 (77\%). The portal metthe students' informational demands, however the perceived usefulness and usability of this educationalresource can be leveraged for broader application in medicine.
\end{abstract}




\section{INTRODUÇÃO}

As novas tecnologias de informação e comunicação, incluindo recursos de conectividade e interatividade como internet, ambientes virtuais de aprendizagem e web-conferência são cada vez mais utilizadas na medicina para complementar a educação tradicional e facilitar o acesso aos recursos e serviços, o intercâmbio e colaboração à distância ${ }^{1-4}$. Diariamente, professores e alunos precisam tomar decisões rápidas baseadas em evidências científicas, experiências e informações atualizadas. Para isso, são necessárias bases de dados relevantes na área de saúde, saber como e onde buscar conteúdos pertinentes para usar as informações disponíveis on-line com eficiência, segurança e ganho de tempo ${ }^{5-7}$.

Pesquisas sobre uso de multimídias e internet na docência médica frente aos métodos tradicionais indicam que o ensino-aprendizagem virtual permite transmitir um corpo doutrinário e obter melhores resultados que a forma magistral tradicional na evolução posterior do conhecimento com mais interatividade, retenção de conteúdos e motivação ${ }^{2,5,8}$. Muitas instituições empregam, na graduação, aprendizagem clínica baseada em evidência, e-learning e internet, utilizando casos clínicos, simulações, jogos, vídeos científicos, conferências, bibliotecas virtuais de saúde e módulos de aprendizagem à distância ${ }^{1,3,4,9-13}$. Estudos sobre uso da internet por estudantes, residentes e professores da área médica mostram uma crescente procura por informação qualificada, confiável, atualizada e de fácil acesso ${ }^{6,10}$.

A tecnologia da informação e comunicação para ensinar e aprender tem imenso potencial para aumentar o acesso, a qualidade e o sucesso da educação superior e o desenvolvimento social $^{14-17}$. A telemedicina ${ }^{1,2,18}$ aplicada ao ensino (teleducação) e serviços primários de saúde (teleassistência) ${ }^{8,11,14}$ apresentam alto índice de efetividade ${ }^{19,20}$. As doenças de pele são prevalentes nos atendimentos na rede do Sistema Único de Saúde, ambulatórios e consultórios, acometendo de $30 \%$ a $55 \%$ da população ${ }^{21,22}$. As afecções cutâneas podem envolver outros sistemas orgânicos, interferir na rotina dos indivíduos, afetar a autoestima, a qualidade de vida e a produtividade, gerando estigma e exclusão social ${ }^{21,23}$. Portanto, é importante que os médicos tenham conhecimentos acerca da Dermatologia em sua prática clínica, constituindoum elemento a ser valorizado na graduação e na educação continuada relacionada à atenção integral.

A teleducação, treinamento ou mesmo tutorização e avaliação do aprendizado usando recursos digitais com embasamento científico e boa relação custo-benefício vêm sedesenvolvendo em especial nas áreas onde a interpretação de imagens é essencial na formulação diagnóstica, como na Der- matologia ${ }^{1,2,18,22,24}$.Objetos de aprendizagem com computação gráfica - como o Homem Virtual (www.projetohomemvirtual. org.br) e o Dermatunel ${ }^{25}$ usando ambiente interativo de aprendizagem - transmitem conhecimentos de forma contextualizada e rápida para a educação médica, bem como promovem a saúde, cultura e qualidade de vida da sociedade. Recentemente, o projeto Cybertutor ${ }^{22}$ empregou casos clínicos dermatológicos e aulas teóricas no ensino dos alunos de graduação, com resultados satisfatórios.

A entrada das novas tecnologias nas salas de aula e a aplicação de recursos como portais educacionais adotados em várias instituições procuram facilitar o trabalho pedagógico do professor e melhorar o desempenho dos alunos ${ }^{26-28}$. Porém, pouco se conhece sobre as possíveis dificuldades ou limitações encontradas pelos graduandos ao navegarem pelo site desses portais para obterem as informações desejadas. Como o curso médico é fundamentado no modelo presencial de ensino, cabe estudar as dimensões deste contexto, centrado na oferta dosrecursos didáticos do portal universitário com ênfase no ensino-aprendizagem da Dermatologia.

\section{MATERIAL E MÉTODOS}

Trata-se de pesquisa transversal de abordagem quantitativa, realizada de outubro a dezembro de 2012, para avaliar o perfil de acesso e uso do portal universitário na disciplina de Dermatologia por estudantes de Medicina em instituição privada no Sul do País. Esse curso é presencial e ocorre em tempo integral, recebendo alunos do contexto nacional e internacional. A disciplina é ofertada de modo semestral a turmas de 30-35 alunos, sendo desenvolvida por meio de atividades teóricas, teórico-práticas e práticas no hospital-escola, com carga horária semanal de três horas e total de 45 horas.

O plano de ensino, integrado ao projeto pedagógico do curso e submetido ao colegiado, é dotado de uma organização racional estabelecida no roteiro estruturado pela instituição, sendo publicado para os alunos após sua aprovação. Funciona como um instrumento didático-pedagógico e administrativo, de elaboração e uso obrigatório, e aponta como as atividades curriculares são conduzidas ao longo de cada disciplina.

Na semana de planejamento pedagógico, realizada todo semestre,é oferecido treinamento e atualização para o uso do portal, quepermite suporte à modalidade presencial e ensino à distância, por meio de diversos recursos e ferramentas, podendo-se tirar dúvidas on-line, por telefone, no manual ou diretamente no setor de informática sempre que necessário. O catálogo de produtos fornecido pela disciplina de Dermatologia no portal constitui um acervo amplo que inclui, além do plano de ensino e conteúdo programático das aulas, técnicas sobre como 
estudar e aprender Dermatologia, conjuntos de slides ilustrados usados nas aulas, roteiros de estudo, referências bibliográficas, textos, artigos, exercícios de múltipla escolha, casos clínicos, links de interesse (atlas, materiais didáticos, sites científicos, revistas on-line), cronograma de atividades e trabalhos, bem como projetos de extensão e oportunidades diversas (cursos, estágios, campanhas, treinamentos) em Dermatologia.

Os alunos possuem senha individual para acesso, flexibilidade e autonomia para interagir com os materiais e as ferramentas digitais e, em caso de dúvida, devem contatar o corpo docente via e-mail institucional ou pessoalmente no período de aulas. O conteúdo das aulas teóricas editadas no portal segue um roteiro estruturado composto de: objetivos, conteúdo, metodologia de ensino, atividades de leitura obrigatória e recomendada, e atividades práticas supervisionadas. As orientações gerais e o contrato pedagógico são apresentados no primeiro dia de aula, ocasião em que é realizado o levantamento das principais expectativas dos alunos em relação à disciplina para estabelecer o diálogo e facilitar o processo educacional. As aulas teórico-práticas e as práticas, também ministradas no ambiente hospitalar, têm o intuito de integrar o conhecimento, atitudes e habilidades com as experiências do dia a dia. São ofertadas, ainda, atividades complementares opcionais em ambiente e horários extracurriculares. Os avisos, comunicações e eventuais mudanças são editados nos espaços específicos para esta finalidade.

A população-alvo desta pesquisa se constituiu de estudantes adultos, de ambos os gêneros, matriculados no curso de Medicina. A seleção da amostra foi não probabilística por conveniência. Como critérios de inclusão foram definidos acadêmico/ estudante/aluno com idade acima de 18 anos, de qualquer cor / raça/etnia/gênero, que já tenha cursado a disciplina de Dermatologia e que aceitasse participar da pesquisa. Os critérios de exclusão foram discentes com idade inferior a 18 anos, alunos que não cursaram essa disciplina, não aceitaram participar da pesquisa ou que eram estudantes temporários fazendo estágio no internato ou programas de intercâmbio internacional.

Os dados foram coletados por meio de um instrumento que continha questões fechadas do tipo questionário, registrado no próprio instrumento e autoaplicado no intervalo das aulas. O mesmo foi composto por dados pessoais, como: sexo, idade, disponibilidade de internet e recursos tecnológicos, redes sociais utilizadas; dados acadêmicos: período do curso de Medicina, hábitos de leitura, domínio de idiomas; dados de acessos e uso do portal, como: frequência, assuntos escolhidos, vantagens e dificuldades encontradas.

O instrumento foi previamente avaliado por dois professores e testado em três alunos não incluídos nesta pesquisa, para verificar sua eficácia e adequação. Os dados foram conferidos e organizados com auxílio do programa Excel. Na análise estatística descritiva foram utilizadas medidas simples, como: distribuição de frequências e percentuais, médias e desvios padrões. Os resultados obtidos no estudo foram apresentados por meio de figuras e gráficos.

O projeto foi aprovado pela Coordenação do Curso de Medicina e Comitê de Ética em Pesquisa (protocolo 99.257 de 17/09/2012).A coleta de dados e a divulgação posterior dos resultados foram explicadas detalhadamente, garantindo a observância dos princípios bioéticos de preservação do sigilo e anonimato.

\section{RESULTADOS}

Do total de 214 alunos elegíveis para o estudo que preenchiam os critérios predeterminados, foram incluídos 122 estudantes que concordaram com a participação por meio de assinatura no termo de consentimento. Desta pesquisa participaram $68 \mathrm{mu}$ lheres $(56,2 \%)$ e $53(43,8 \%)$ homens na faixa etária de $23,7 \pm 3,1$ anos (mínimo de 20, máximo de 42 e mediana de 23 anos). Esses acadêmicos estavam distribuídos entre o terceiro e o sexto ano do curso, dentre os quais 45 alunos $(37,2 \%)$ cursavam o oitavo período e $34(28,1 \%)$ tinham acabado de completar a disciplina.

Vinte $(16,4 \%)$ estudantes chegaram a iniciar outro curso superior antes, em especial na área da Saúde. Em relação ao domínio de idiomas (leitura, oralidade e escrita),verificou-se registro de proficiência em inglês por 114 (93,4\%) estudantes, em espanhol por $60(49,2 \%)$, em francês por $8(6,6 \%)$, em alemão por $2(1,6 \%)$. Três estudantes possuíam proficiência em japonês, italiano e holandês, um em cada idioma,respectivamente.

O hábito de leitura predominante empregado para estudo,identificado nesta amostra,foi a opção da mídia impressa e digital. Em trabalhos e pesquisas acadêmicos, foram usados artigos de periódicos por 108 (88,5\%) estudantes, guidelines por $96(78,7 \%)$, livros por $90(73,8 \%)$, textbooks por 22 $(18 \%)$ e outros por $9(7,4 \%)$ alunos. Nestes outros, foram mencionados Google acadêmico e Wikipédia.

As principais bases de dados acessadas pelos participantes neste estudo foram UpToDate por 103 (84,4\%) acadêmicos, Pubmed por 95 (77,9\%), Scielo por 94 (77\%), Medline por 59 (48,4\%) Cochrane por 24 (19,7\%), Lilacs por 20 (16,4\%), Bireme por $20(16,4 \%)$, Portal Capes por $13(10,7 \%)$, Web of Science por $4(3,3 \%)$, ACP Medicine por 1(0,8\%) e outras bases por 21 $(17,2 \%)$ estudantes.

Em relação ao arsenal de equipamentos eletrônicos próprios, notebook foi registrado por 106 alunos (86,9\%), celular por $69(56,6 \%)$, smartphone por $59(48,4 \%)$, desktop por36 $(29,5 \%)$ e tablet por $22(18 \%)$ acadêmicos. Cento e vinte e um 
$(99,2 \%)$ estudantes possuíam pelo menos um equipamento eletrônico particular para uso individual. Quanto à participação em redes sociais, Facebook foi preferida por 115 (94,3\%) acadêmicos, sendo que 26 (21,3\%) estudantes utilizavam também outras redes (Twitter, Orkut, Linkedin, etc.).

Os recursos de comunicação diários mais utilizados pelos alunos foram: Facebook por 114 (93,4\%), Skype por $42(34,4 \%)$, MSN por $37(30,3 \%)$ e GTalk por $2(1,6 \%)$. A maioria dos estudantes possuía pelo menos um endereço de $e$-mail, porém nenhum blog ou outro tipo de página pessoal na internet foi mencionado.

Nesta pesquisa, observou-se que o plano de ensino foi acessado uma vez no mês por 12 (9,8\%)estudantes e uma vez na semana por $14(11,5 \%)$ acadêmicos. Entretanto, o conteúdo programático das aulas foi conferido uma vez no mês por 54 $(32,8 \%)$ estudantes e uma vez na semana por $23(18,9 \%)$ acadêmicos.

Os conjuntos de slides ilustrados das aulas foram acessados uma vez no mês por 26 (21,3\%) estudantes, a cada 15 dias por $28(23 \%)$ e uma vez na semana por 50 (41\%) acadêmicos. Quanto aos textos e artigos anexados no portal, ${ }^{66}$ (54,1\%) estudantes consultavam este material uma vez no mês no decorrer do período letivo.

Já os exercícios de fixação da aprendizagem para estudo individual prévio eram procurados uma vez no mês por 33
(27\%) estudantes, a cada 15 dias por 12 (9,8\%) e uma vez na semana por5 $(4,1 \%)$ acadêmicos durante o semestre em que estiveram matriculados na disciplina (Gráfico 1).

Os eventos e as oportunidades em Dermatologia divulgados pelo portal foram consultados uma vez no mês por 26 (21,3\%) estudantes, a cada 15 dias por 17 (13,9\%) e uma vez na semana por $16(13,1 \%)$ acadêmicos. Os projetos de extensão da disciplina registravam acessos uma vez no mês por $25(20,5 \%)$ estudantes, a cada 15 dias por $10(8,2 \%)$ e uma vez na semana por $8(6,6 \%)$ acadêmicos.

Orientações on-line sobre técnicas de estudo em Dermatologia foram consultadas uma vez no mês por 26 (21,3\%) estudantes, a cada 15 dias por $3(2,5 \%)$ e uma vez na semana por $6(4,9 \%)$ acadêmicos. O contrato pedagógico da disciplina foi verificado uma vez no mês por $13(10,7 \%)$ estudantes, a cada 15 dias por $3(2,5 \%)$ e uma vez na semana por $6(4,9 \%)$ acadêmicos.

As leituras obrigatórias disponibilizadas em forma de textos foram acessadas uma vez no mês por 37 (30,3\%) estudantes, a cada 15 dias por 28 (23\%) e uma vez na semana por $18(14,8 \%)$ acadêmicos. Em relação às leituras complementares indicadas no portal, identificou-se acesso uma vez no mês por 33 (27\%) estudantes, a cada 15 dias por 29 (23,8\%) e uma vez na semana por $8(6,6 \%)$ acadêmicos durante o semestre no qual cursavam a disciplina (Gráfico 2).

\section{GrÁFICO 1}

Acesso e uso do portal pelos universitários quanto ao plano de ensino, conteúdo programático, aulas, artigos e exercícios $(\mathrm{n}=122)$

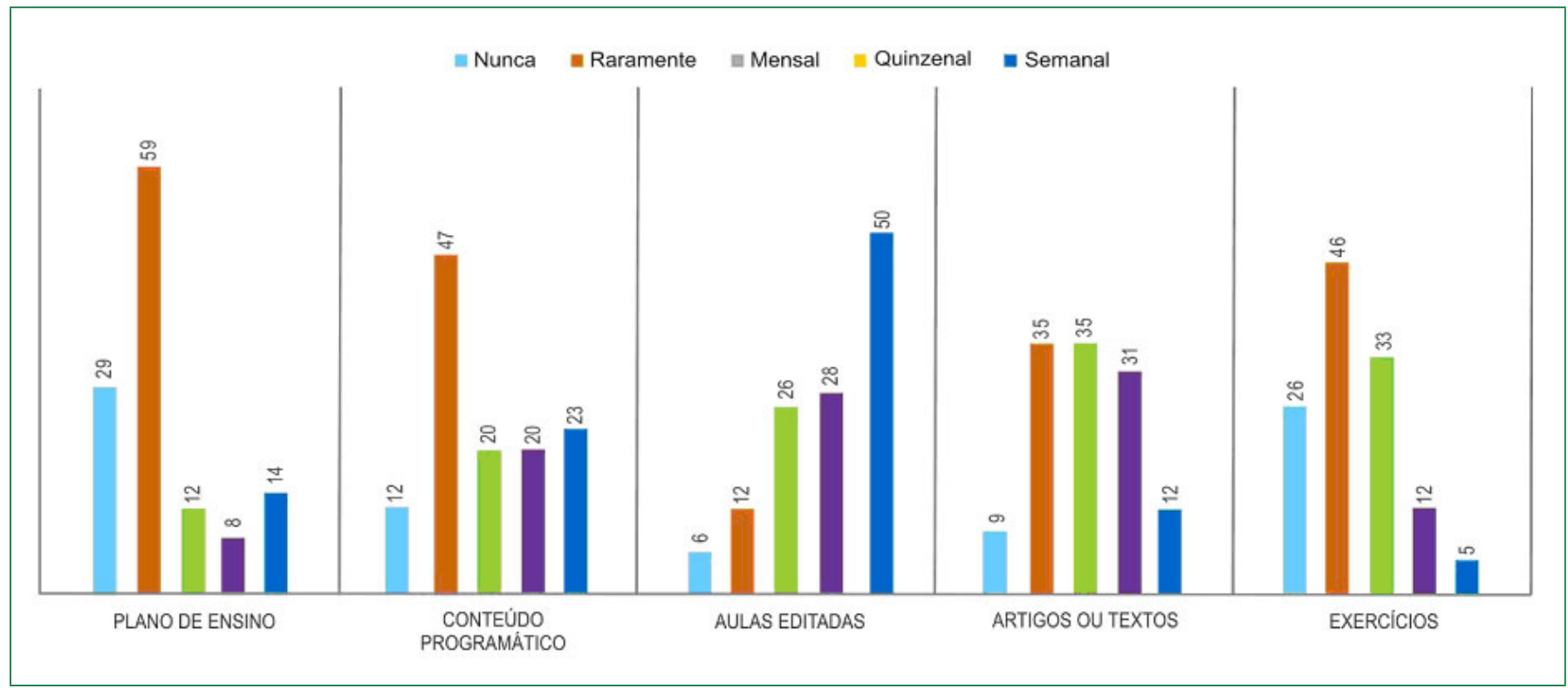




\section{GRÁfICO 2}

Acesso e uso do portal pelos universitários quanto ao contrato pedagógico, leituras obrigatórias, leituras complementares, técnicas de estudo e projetos de extensão $(n=122)$

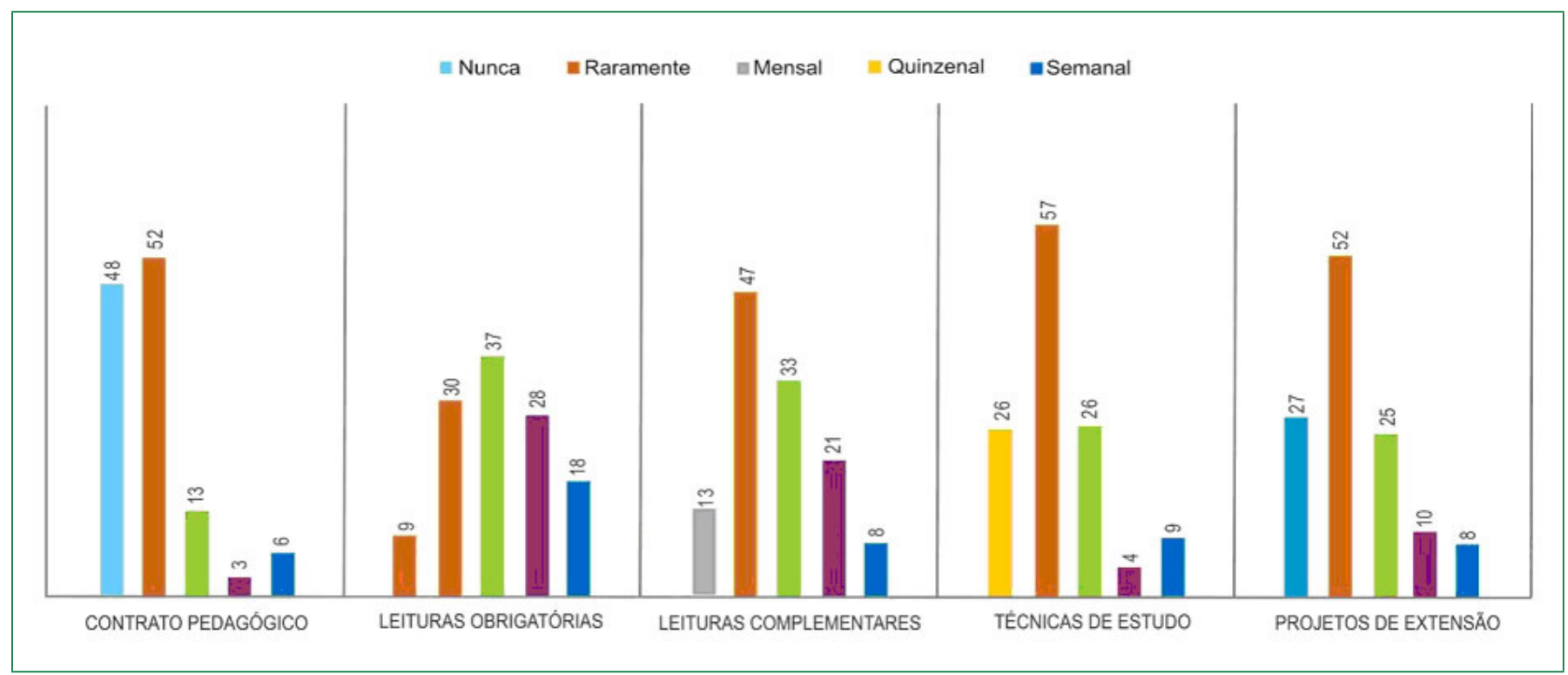

Consultas a bibliotecas virtuais e revistas médicas indicadas foram realizadas uma vez no mês por $34(27,9 \%)$ estudantes, a cada 15 dias por 29 (23,8\%) e uma vez na semana por 15 $(12,3 \%)$ acadêmicos durante a disciplina.

Avisos editados pelo corpo docente mostravam acessos uma vez no mês por 19 (15,6\%) estudantes, a cada 15 dias por $29(23,8 \%)$ e uma vez na semana por 40 (32,8\%). Da mesma forma, avisos editados pela coordenação de Medicina foram acessados uma vez no mês por $16(13,1 \%)$ estudantes, a cada 15 dias por $18(14,8 \%)$ e uma vez na semana por $43(35,2 \%)$ acadêmicos.

O link para o portal da Sociedade Brasileira de Dermatologia foi acessado uma vez no mês por 18 (14,8\%) estudantes, a cada 15 dias por $4(3,3 \%)$ e uma vez na semana por $6(4,9 \%)$ acadêmicos. Links para sites especiais de atlas de lesões de pele foram consultados uma vez no mês por 26 (21,3\%) estudantes, a cada 15 dias por $8(6,6 \%)$ e uma vez na semana por $7(5,7 \%)$ acadêmicos durante o período letivo da disciplina.

O cronograma de aulas da Dermatologia foi acessado uma vez no mês por 31 alunos (25,4\%), a cada 15 dias por $21(17,2 \%)$ e uma vez na semana por $17(13,9 \%)$ acadêmicos. O cronograma de provas, seminários e trabalhos foi acessado uma vez no mês por 44 alunos (36,1\%), a cada 15 dias por 29 (23,8\%) e uma vez na semana por 25 (20,5\%) estudantes durante o semestre (Gráfico 3).
O acesso ao portal universitário foi preferencialmente realizado pela internet da própria casa por 95 (77,9\%) alunos, por intermédio de celular/smartphone/tablet e outros dispositivos móveis por $53(43,4 \%)$ estudantes, por meio da biblioteca no campus por $16(13,1 \%)$ e no hospital-escola por $6(4,9 \%)$ acadêmicos.

A quantidade de informações disponíveis foi muito importante para $53(43,5 \%)$ alunos, atualidade e oportunidade de informações para 59 (48,4\%),facilidade de utilização da rede para $62(50,8 \%)$, gratuidade e disponibilidade permanente de material didático para $64(68,8 \%)$ estudantes, recursos oferecidos para 67 (54,9\%) e obtenção de slides de aulas para $95(77,8 \%)$ acadêmicos durante o semestre em que cursaram a disciplina de Dermatologia (Gráfico 4).

As principais dificuldades encontradas se relacionaram às instruções no manejo dos recursos do portal para 12 (9,8\%)alunos, utilização e configuração da rede para 23 (18,8\%), baixa velocidade de resposta para 37 (30,3\%) estudantes,acesso fora do ambiente da universidade para 16 (13,1\%), disponibilidade de internet no hospital-escola para 35 (28,7\%) acadêmicos durante o período letivo (Gráfico 5).

As barreiras no acesso e uso do portal elencadas foram divulgação dos recursos oferecidos para $21(17,2 \%)$, lentidão no acesso para 36 (28,6\%), condições técnicas ou operacionais de conexão para 35 (28,7\%), localização de determinada informa- 
GRÁFICO 3

Acesso e uso do portal pelos universitários quanto ao cronograma de aulas, cronograma de provas e trabalhos, avisos e atlas de lesões de pele $(n=122)$

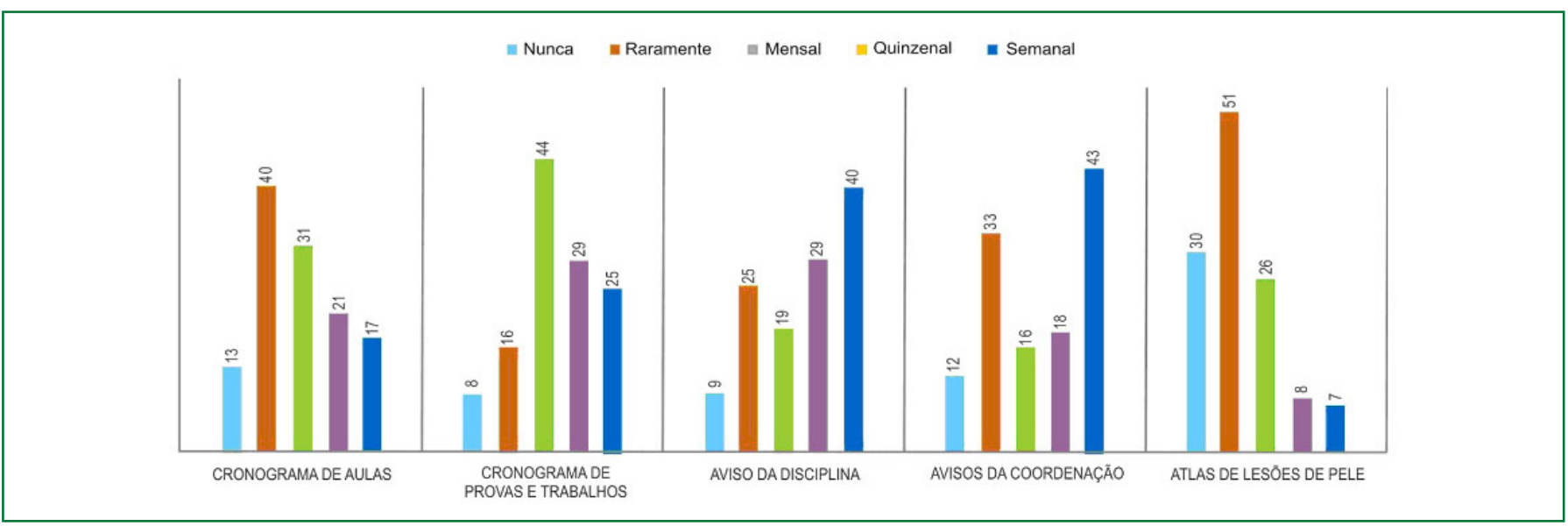

Gráfico 4

Identificação das vantagens de uso do portal universitário $(\mathrm{n}=122)$

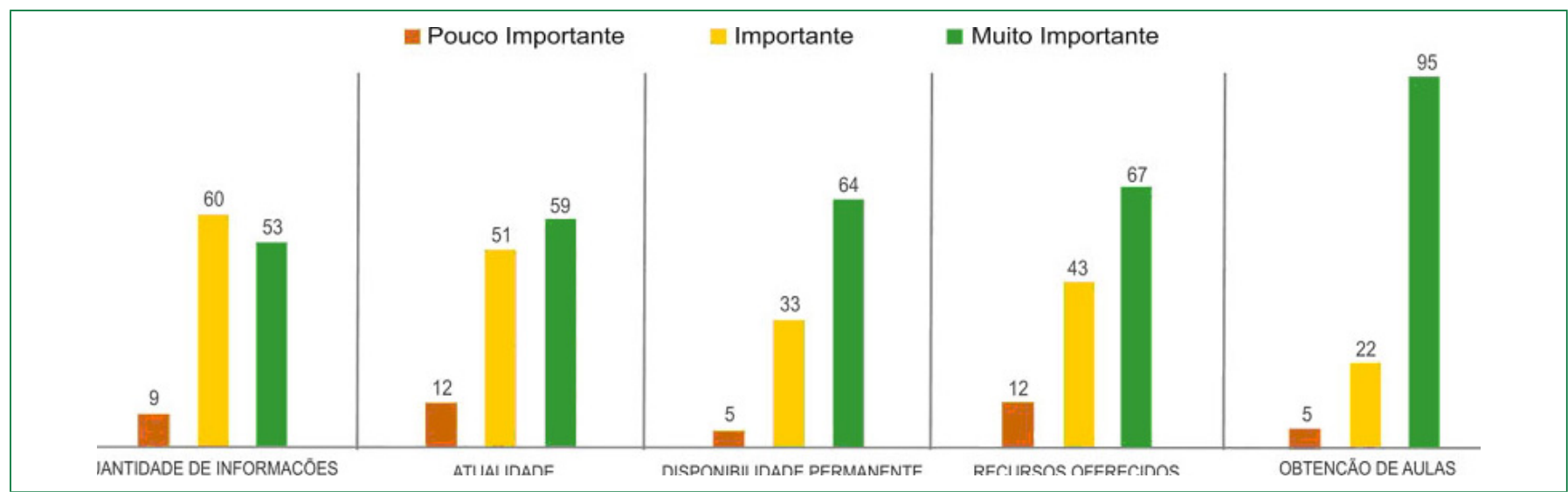

GRÁfICO 5

Identificação das dificuldades de uso do portal quanto a instruções, configuração, velocidade, acesso fora da universidade e disponibilidade de rede no hospital-escola $(n=122)$.

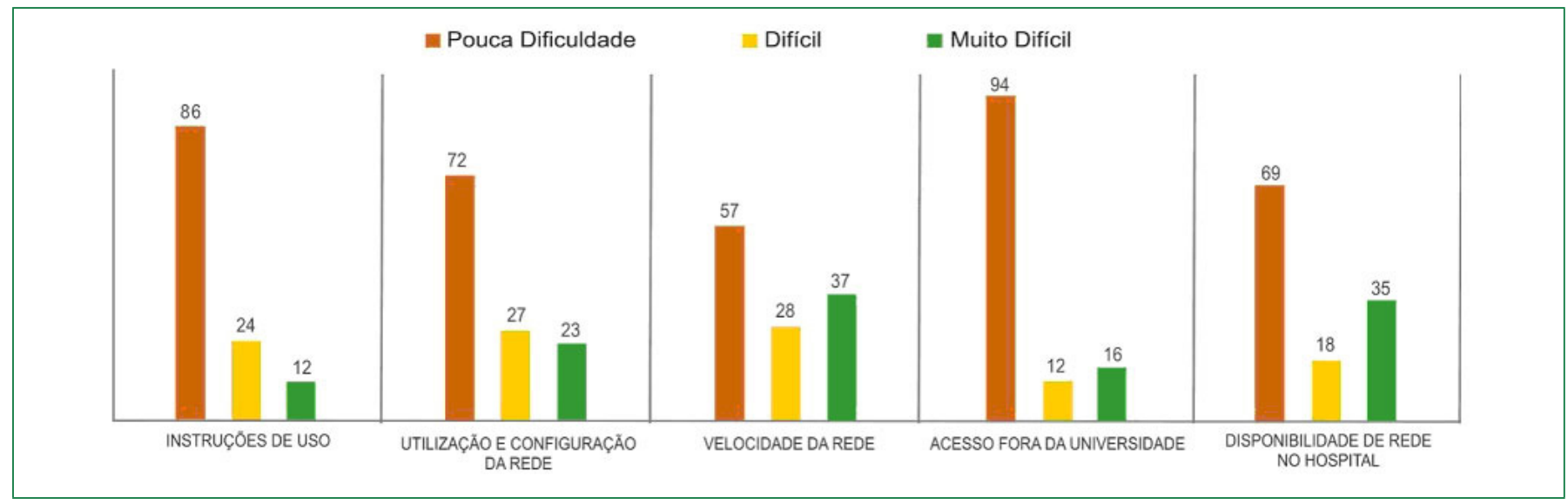




\section{GRÁFICO 6}

Identificação das dificuldades de uso do portal quanto à divulgação dos recursos, aspectos técnico-operacionais, localização das informações, tempo gasto nos acessos e material desejado $(n=122)$

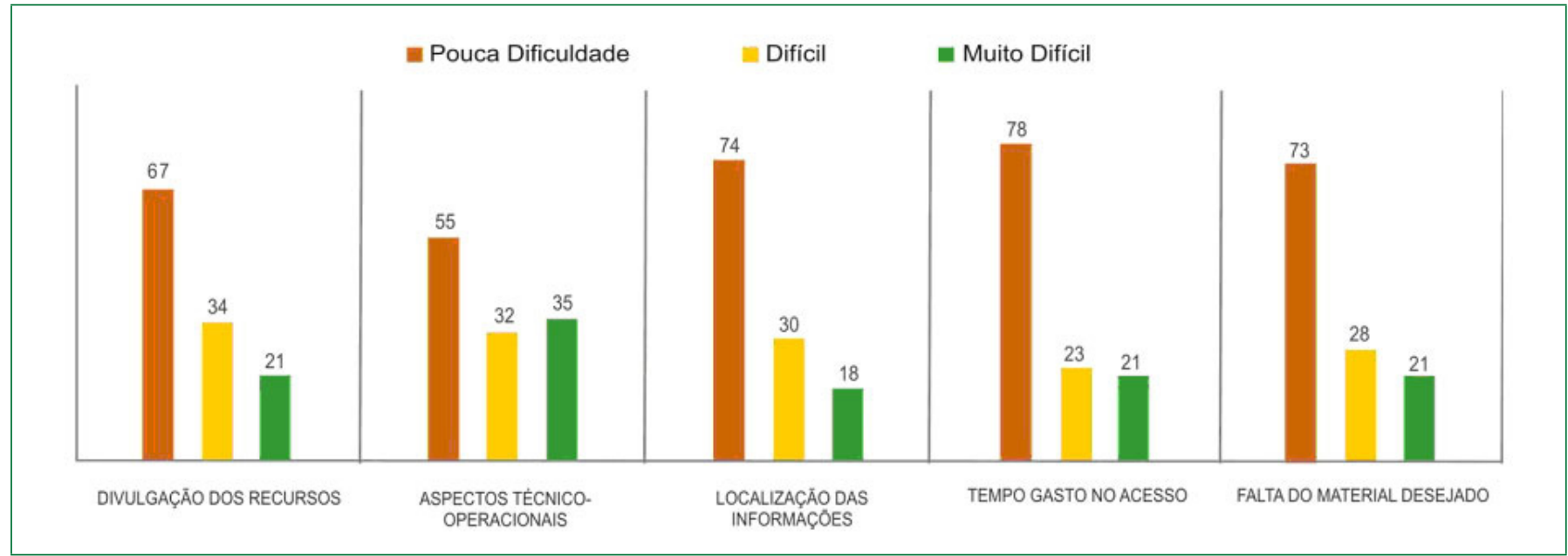

ção para $18(14,8 \%)$, excesso de tempo gasto nos acessos para $21(17,2 \%)$ e falta do material desejado para $21(17,2 \%)$ alunos (Gráfico 6).

$\mathrm{O}$ uso frequente do acervo da Dermatologia durante o semestre em que foi ofertada a disciplina foi referido por 64 $(52,5 \%)$ alunos, mas a leitura anterior da aula só foi mencionada por $18(14,8 \%)$ estudantes. Entretanto, na semana de provas, a frequência de acesso e uso do material de aulas no portal foi registrada por 96 (78,7\%) acadêmicos.

O acervo disponibilizado no portal é armazenado em arquivo digital por 110 (90,2\%) alunos, impresso para montagem de apostila por $16(13,1 \%)$ estudantes, repassado para amigos de outras instituições por $2(1,6 \%)$, deletado por $2(1,6 \%)$ e destino não identificado por $4(3,3 \%)$ acadêmicos. Não houve registro de divulgação das aulas na internet em nenhum dos questionários respondidos pelos participantes deste estudo.

O portal universitário atendeu as necessidades informacionais de estudo na disciplina de Dermatologia completamente para $51(41,8 \%)$ alunos e parcialmente para $65(53,3 \%)$ estudantes. Seis acadêmicos alegaram que suas necessidades não foram atendidas pelo portal durante o semestre no qual cursaram a disciplina.

\section{DISCUSSÃO}

O acesso e o uso das mídias e tecnologias são uma realidade mundial crescente e estão causando grandes impactos na educação $\mathrm{O}^{1,11,15,18}$. No processo de ensino-aprendizagem, a busca, o acesso e o uso de fontes educacionais idôneas facilitam a solução de problemas informacionais, integração, interdisciplina- ridade e flexibilização nesta era globalizada e tecnológica ${ }^{10,15-17}$. É necessário, portanto, conhecer os recursos disponíveis utilizados e pertinentes. Este estudo se propôs a conhecer o acesso e uso do portal universitário no ensino da Dermatologia na graduação oferecida por instituição privada no Sul do País.

O grupo foi composto por estudantes de Medicina, considerando os critérios de inclusão e participação voluntária. Foram inseridos 122 indivíduos com idades entre 20 e 42 anos, média de 23 anos e predomínio do gênero feminino. A maior tendência de mulheres e de público jovem no curso de Medicina é compatível coma literatura ${ }^{10}$.

Ao se analisar o perfil dos respondentes, verificou-se que os alunos do quarto ano tiveram maior número de representantes, o que possivelmente se deve a sua convivência mais recente com a disciplina. A menor concentração de alunos do quinto e sexto ano pode ser atribuída a atividades em outros cenários de aprendizagem durante o internato. No entanto, houve participação de alunos de todos os anos que já cursaram Dermatologia,o que significa que, independentemente do ano, os estudantes se preocuparam em dar um retorno sobre a pesquisa relacionada ao portal e à disciplina.

Quanto às características tecnológicas destes estudantes, verifica-se grande disponibilidade de equipamentos pessoais, entre os quais se destaca o notebook. A participação em redes sociais e a familiaridade com recursos de internet são traços comuns no grupo, que apresenta alta taxa de comunicação utilizando Facebook e e-mail. Esses dados estão em conformidade com estudos realizados entre jovens com faixa etária semelhante ${ }^{10}$ e com médicos residentes ${ }^{3,6}$. 
Nesta pesquisa, verifica-se alta prevalência de estudantes com hábitos de leitura em mídia impressa e digital. Provavelmente, essas habilidades pessoais de ler, escrever e entender, consideradas matéria-prima para aquisição de informações, auxiliam na geração de conhecimentos em conjunto com a disponibilidade e acessibilidade dos recursos tecnológicos ${ }^{1,2,18}$. Em concordância com a literatura ${ }^{3,10,22}$, a combinação de tecnologia com métodos tradicionais de ensino incentiva o estudante a gerenciar ativamente seu papel como aluno.

$\mathrm{O}$ uso da internet vem abrindo importantes fronteiras para a educação ${ }^{15}$, e as bibliotecas disponíveis em ambiente eletrônico ${ }^{10}$ podem aumentar a produtividade e adicionar valor ao trabalho dos professores e alunos. Neste estudo, identificou-se que a maioria dos acadêmicos consulta periódicos para revisões e pesquisas, bem como bases de dados consagradas na Medicina, como UpToDate, Pubmed e Scielo. Este fato se justifica pelo forte estímulo à apresentação de seminários como parte do ensino e avaliação, preparação de pesquisas para eventos técnico-científicos e uso de guidelines na assistência médica, tanto na disciplina como no curso em geral.

Em relação aos sistemas informatizados utilizados com frequência, a maior procura pelo UpToDate se mostrou semelhante ao estudo de Savi e Silva ${ }^{6}$. Os fatores relevantes para o desempenho destas atividades pelos estudantes avaliados podem estar associados às competências e habilidades linguísticas para transpor as barreiras idiomáticas e facilitar a busca e o uso da informação localizada.

Quanto às necessidades informacionais dos alunos, identificou-se que a preferência de acesso durante a disciplina de Dermatologia obedeceu à seguinte ordem de interesse: (1) aulas editadas; (2) cronograma de provas e trabalhos; (3) avisos editados pelo corpo docente; (4) leituras obrigatórias; (5) artigos, textos anexados e consultas a bibliotecas virtuais e revistas médicas indexadas; (6) avisos editados pela coordenação da Medicina; (7) conteúdo programático das aulas;(8) leituras complementares; (9) divulgação de eventos e oportunidades em Dermatologia; (10) exercícios individuais de fixação da aprendizagem.

Nesta pesquisa, esses dez itens provavelmente correspondem a áreas de demandas específicas, uma vez que todo o material pode ser acessado de forma livre e gratuita. A política de seleção na escolha é direcionada pelo próprio aluno,mas pode sofrer influência da utilidade percebida e facilidade de uso, ou seja, ser determinada pela maneira como estes recursos são incorporados ao cotidiano do acadêmico.

O plano de ensino e o conteúdo programático referente à Dermatologia seguem as Diretrizes Curriculares Nacionais preconizadas pelo Ministério da Educação para a formação geral do médico ${ }^{22}$. Na presente investigação, verificou-se que o item plano de ensino da disciplina, disponibilizado no portal para facilitar a transposição pedagógica,foi muito pouco acessado pelos estudantes. Provavelmente, modificações na sua representação gráfica e maior suporte didático de compartilhamento durante o semestre poderiam melhorar sua apropriação pelos discentes.

$\mathrm{O}$ acesso ao portal universitário predominou do ambiente de casa, seguido de celular/smartphone/tablet e outros dispositivos móveis. Analisando essa situação, ressalta-se que,possivelmente, o uso de tecnologia wi-fi ou 3G auxiliou no processo durante as aulas realizadas no hospital-escola. Sob o foco da logística e estratégia, é importante considerar os fatores tempo, espaço, adequação e otimização dos processos para aumentar a sincronia com os benefícios advindos do portal ao programa educacional.

Neste estudo, as principais vantagens identificadas pelos estudantes para o uso do portal foram obtenção de aulas ilustradas, recursos oferecidos, gratuidade e disponibilidade permanente de materiais didáticos. As principais barreiras encontradas se referiram a baixa velocidade, utilização e configuração da rede e aspectos técnico-operacionais da internet no hospital-escola. Esta questão provoca reflexão sobre como o estudante interage com o portal diante dessas dificuldades ao considerar a importância do conteúdo disponibilizado e o potencial de uso em sala de aula. Diante dessas informações, acredita-se que a instituição poderia estimular maior uso do portal no ambiente hospitalar, facilitando o acesso e interação com este sistema, a fim de minimizar esses bloqueios.

Por outro lado, a leitura anterior da aula e do material ofertado foi realizada com frequência por apenas 18 (14,8\%) estudantes durante o semestre letivo. O panorama se modificava na semana de provas, na qual se observa que o acesso ao acervo aumenta em 5,3 vezes a demanda e mobiliza 96 (78,7\%) alunos. Possivelmente, isto sobrecarrega o sistema e prolonga o tempo gasto no acesso ao portal durante esse período do calendário acadêmico.

Embora a disponibilização prévia das aulas vise incentivar os alunos a se preparar melhor, conhecer o tema que será abordado e ler os materiais recomendados com antecedência, este fato nem sempre foi observado. $\mathrm{O}$ aproveitamento mais adequado das aulas, exercícios e recursos disponibilizados no portal pelos estudantes possibilitaria dinamizar o tempo de aula, voltando-a para discussões mais profundas e para o esclarecimento de dúvidas ${ }^{16,26,27}$. Mais do que isso, os alunos poderiam se organizar para usar estes recursos de forma mais dinâmica e interativa.

Odestino dadoao acervo da disciplina de Dermatologia,em sua maioria,foi o armazenamento em arquivo digital, embora 
$16(13,1 \%)$ estudantes o transformem em apostila e 2(1,6\%) afirmem repassar para amigos. Em quatro questionários, essa informação foi assinalada como "outros" sem especificar que tipo de destino. Apesar da ausência de registro de divulgação dos recursos didáticos da disciplina na internet, verifica-se que parte deste acervo está livre na rede em endereços eletrônicos de alunos, da turma ou de seus representantes, bem como no Facebook.

No presente estudo, a maioria dos acadêmicos identificou que o portal universitário, da forma como estava funcionando durante o período letivo, atendeu as necessidades informacionais de modo parcial ou completo. Questionam-se os motivos que levaram seis alunos a alegar que suas necessidades informacionais não foram atendidas pelo portal durante a disciplina. Entre as possíveis explicações está a abordagem metodológica utilizada na prática da sala de aula,que prioriza desenvolver habilidades e competências individuais e coleti$\operatorname{vas}^{26-28}$. O portal não substitui todos os aspectos inerentes ao trabalho multidimensional realizado nos diversos cenários de aprendizagem do curso de Medicina. Outra justificativa é o grau de exigência e expectativas destes estudantes e ainda a rapidez e simplicidade com que se pode obter informação científica e técnica na internet.

O portal como ferramenta didática auxiliou a prática pedagógica e o processo de ensino da Dermatologia. Entretanto, a aprendizagem entendida como processo conceitual, metodológico, atitudinal e valorativo é individual. Neste contexto, o conhecimento não é transferido, mas, sim, construído a partir da atividade do sujeito sobre o mundo. Isto porque quem atribui significado e sentido aos conteúdos é o próprio aprendiz, numa tarefa que ninguém pode realizar por ele ${ }^{29}$.

Segundo a Conferência Mundial sobre Ensino Superior 2009 promovida pela United Nations Educational, Scientific and Cultural Organization ${ }^{15}$ :

É importante investir na educação superior como força maior na construção de uma sociedade inclusiva e de conhecimento diversificado... além de avançar em pesquisa, inovação e criatividade... A educação superior não deve apenas fornecer práticas sólidas para o mundo presente e futuro, mas deve também contribuir para a educação de cidadãos éticos, comprometidos com a construção da paz, com a defesa dos direitos humanos e com os valores da democracia (p.2.)

Cabe ressaltar que a presente pesquisa apresenta limitações referentes ao tamanho amostral e restrição a uma instituição peculiar, sendo presumível que alunos de Medicina focalizados em outras universidades e contextos geográfi- cos facultem padrões empíricos distintos dos aqui colhidos. Entende-se que é um conjunto de fatores que faz a relação da tecnologia e da mídia no sistema educacional dar certo ${ }^{3,30}$. Porém,tendo em vista o importante acervo disponibilizado no portal universitário como instrumento de apoio aos propósitos educacionais e considerando que todos os estudantesdesta amostra navegam com frequência nas redes, é preciso rever a baixa velocidade de transmissão e as dificuldades técnicas operacionais alegadas. Este fato pode ser um indicador útil para o planejamento estratégico de ações que visem integrar melhor o ensino presencial com os recursos didáticos à distância ${ }^{6,17,22,28}$.

Este estudo ajudou a compreender como essa nova geração deacadêmicos de Medicina se relaciona com o portal universitário e a internet para atividades ligadas ao ensino médico, à pesquisa bibliográfica e à consulta a banco de dados virtuais, bem como contribuiu com a identificação das redes sociais mais usadas nas comunicações e relações interpessoais on-line. Espera-se que o conhecimento e a reflexão acerca da realidade encontrada possam melhorar o ensino-aprendizagem na Dermatologia, diminuindo perdas pelo uso inadequado ou incompleto dos serviços e aplicativos do portal e, em especial, da internetnas inovações e sustentabilidade no campo da Medicina ${ }^{14,15,28,30}$. Diante das possibilidades pedagógicas destas ferramentas, pode-se melhorar a participação do aluno no processo de construção do conhecimento e, ainda, defender uma integração criativa- e não apenas reativa ao mercado - das tecnologias de informação e comunicação disponíveis aplicadas à educação médica.

\section{CONCLUSÃO}

Nesta amostra, predominaram adultos jovens do gênero feminino,que cursavam o quarto ano de Medicina com bom domínio linguístico e digital. O local de acesso preferencial ao portal foi a internet em domicílio, seguido de dispositivos móveis. As principais vantagens destacadas pelos alunos foram acesso ao material ilustrado das aulas, recursos oferecidos e disponibilidade permanente de informações. As dificuldades expostas quanto ao manuseio do portal consistiram em disponibilidade de rede no hospital-escola, lentidão, conexão, utilização e configuração, relacionadas aos aspectos técnico-operacionais. Houve grande variabilidade no acesso e uso dos recursos didáticos e conteúdos on-line disponibilizados durante o semestre, sendo que os conjuntos de slides de aulas se destacaram na preferência de acesso. As necessidades informacionais dos estudantes na disciplina de Dermatologia foram supridas pelo portal universitário, porém a utilidade percebida e a facilidade de uso podem ser aprimoradas. 
Este trabalho é resultante da monografia apresentada ao Curso de Especialização em Educação à Distância realizada na Universidade Federal do Paraná.

\section{REFERÊNCIAS}

1. Chao LW, Silveira PS, Böhm GM. Telemedicine and education in Brazil. J TelemedTelecare. 1999;5:137-8.

2. Soirefmann M, Blom MB, Leopoldo L, Cestari T. Telemedicina: uma revisão da literatura. Rev HCPA 2008;28(2):116-9.

3. Tanaka PP, Hawrylyshyn KA,Macario A. Uso de tablet (ipad $\left.{ }^{\circledR}\right)$ como ferramenta para ensino da anestesiologia em estágio de ortopedia. Rev. Bras. Anestesiol. 2012;62(2):21422.

4. Wen CL. Telemedicina e Telessaúde: Um panorama no Brasil. Revista iP. 2008; 10 (2) [capturado em: 02 out. 2013]; 0715.Disponível em:www.ip.pbh.gov.br/ANO10_N2_PDF/ telemedicina_telesaude.pdf.

5. Kaliyadan F. Undergraduate dermatology teaching in India: Need for change. Indian J DermatolVenereolLeprol. 2010;76(5):455-77.

6. Savi MGM, Silva EL. O uso da informação e a prática clínica de médicos residentes. Perspect ciênc inf.2011;16(3):23254.

7. Ciol R, Beraquet VSM. Evidência e informação: desafios da medicina para a próxima década. Perspect. ciênc. inf. 2009;14(3):221-30.

8. Ellaway R, Masters K. AMEE Guide 32: E-Learning in medical education Part 1: Learning, teaching and assessment. Med Teach. 2008;30:455-73.

9. Alvarez C, Brown C, Nussbaum M. Comparative study of netbooks and tablet PCs for fostering face-to-face collaborative learning. Comput Hum Behav.2011; 27(2):834-44.

10. Silva PM, Dias GA, Sena Junior MR, Almeida J. A utilização e aceitação tecnológica da biblioteca virtual em saúde (BVS) nas escolas de medicina da região metropolitana do Recife. Informação \& Sociedade: Estudos. 2009;19(3) [capturado em: 24 set 2013];99-107. Disponível em: <http:/ / www.ies.ufpb.br/ojs2/index.php/ies/article/ view $/ 2962 / 3130>$.

11. Mariani AW, Terra RM, Pêgo-Fernandes PM. E-learning: de ferramenta útil a indispensável. DiagnTratamento. 2013;18(1):3-4.

12. Lerouge C, Garfield MJ, Collins RW. Telemedicine: Technology mediated service relationship, encounter or something else? Int J Med Inform. 2012;8:622-36.

13. Patel BK, Chapman CG, Luo N, Woodruff JN, Arora VM. Impact of Mobile Tablet Computers on Internal Medicine Resident Efficiency. ArchIntern Med.2012;172(5): 436-38.
14. Brasil. Ministério da Saúde. Portaria nº 2.546, de 27 de outubro de 2011. Redefine e amplia o Programa Telessaúde Brasil, que passa a ser denominado Programa Nacional Telessaúde Brasil Redes (Telessaúde Brasil Redes). Diário Oficial da República Federativa do Brasil, Brasília; 2011. Seção 1, n. 208, p. 50-51.

15. UNESCO. Organização das Nações Unidas para a Educação. Ciência e Cultura. Conferência Mundial sobre Ensino Superior 2009: As novas dinâmicas do ensino superior e pesquisas para a mudança e o desenvolvimento social. Paris, 2009. Disponível em: <portal.mec.gov.br/index.php?option=com docman\&task...95>. [Capturado em: 24 set.2013].

16. Amem BMV, Nunes LC. Tecnologias de Informação e Comunicação: Contribuições para o Processo Interdisciplinar no Ensino Superior. Revbraseduc med.2006;29,30(3):171- 80.

17. Belloni ML. A integração das tecnologias de informação e comunicação aos processos educacionais. In: Tecnologias educacionais e educação à distância: avaliando políticas e práticas.2.ed. Rio de Janeiro: Quartet; 2003.

18. Miott HA, Paixão MP, Wen CL. Teledermatologia - passado, presente e futuro. AnBrasDermatol. 2005;80(5):523-32.

19. Zanini M. Análise da concordância diagnóstica entre o diagnóstico presencial e o teledermatológico. Medcután ibero-lat-am. 2013;41(2):60-2.

20. Silva CS, Souza MB, Duque IA, Medeiros LM, Melo NR, Araújo CA, Criado PR. Teledermatologia: correlação diagnóstica em serviço primário de saúde. AnBrasDermatol. 2009;84(5):489-93.

21. Gomes TM, Moura ATMS, Aguiar AC. Dermatologia na atenção primária: um desafio para a formação e prática médica. Revbraseduc med.2012;36(1):125-28.

22. Soirefmann M, Boza JC, Comparin C, Cestari TF, Wen CL. Cybertutor: um objeto de ensino na Dermatologia. An. Bras. Dermatol. 2010;85(3): 400-2.

23. Penha AP, Milano GT, Guimarães TP, Amaral Filho RCG, Cruz RCS. Diagnóstico porTeledermatologia em paciente do Alto Rio Solimões: um caso de escabiose crostosa. Rev. Bras. Med.Fam. Comunidade. 2013; 8(27):127-31.

24. Paixão MP, Miot HA, de Souza PE, Haddad AE, Wen CL. A university extension course in leprosy: telemedicine in the Amazon for primary healthcare. J TelemedTelecare. 2009;15:64-7.

25. Paixão MP, Miot HA, Oliveira Filho J, Wen CL. Dermatúnel: modelo de ambiente interativo de aprendizagem em dermatologia. Saude soc.2009;18(4):800-8.

26. Marzano RJ, Pickering DJ, Pollock JE. Ensino que funciona: estratégias baseadas em evidências para melhorar o desempenho dos alunos. Porto Alegre: Artmed; 2008. 
27. Carlini AL. Procedimentos de ensino; escolher e decidir. In: Scarpato MT, org. Os procedimentos de ensino fazem a aula acontecer. São Paulo: Avercamp; 2004.

28. Semenovitch I. Teledermatologia: contribuições para o diagnóstico das doenças dermatológicas à distância. In: Lupi O, Cunha PR. Rotinas de diagnóstico e tratamento da Sociedade Brasileira de Dermatologia.2.ed. Itapevi (SP): AC Farmacêutica; 2012.

29. Fiorentini LMR. Materiais escritos nos processo formativos à distância. In: Almeida MEB,Moran JM, org. Integração das Tecnologias na Educação Superior. Brasília: MEC; SEED;2005. p.159-165.

30. WHO. Telemedicine: Opportunities and developments in Member States - a report on the second global survey on eHealth, Global Observatory for eHealth series Volume 2. Switzerland 2010.Disponível em: <http://www. who.int/goe/publications/goe_telemedicine_2010. pdf $>$ [capturado em: 4 out.2013].

\section{CONFLITO DE INTERESSES}

Declaro que não houve financiamento para este estudo, mas declaro que tenho vinculo empregatício de professora na Universidade Positivo.

\section{ENDEREÇO PARA CORRESPONDÊNCIA}

Kátia Sheylla Malta Purim

Clinica Jardins

Av. Silva Jardim, 2121

Batel - Curitiba

CEP: 80730-440 - PR

E-mail: kspurim@gmail.com 